\title{
Plantar fasciitis in athletes: diagnostic and treatment strategies. A systematic review
}

\author{
Federica Petraglia ${ }^{1}$ \\ lleana Ramazzina ${ }^{2}$ \\ Cosimo Costantino 3
}

1 Physical Medicine and Rehabilitation School, University of Parma, Italy

2 Department of Biomedical, Biotechnological and Translational Sciences, University of Parma, Italy

3 Department of Biomedical, Biotechnological and Translational Sciences, University of Parma, Italy

Corresponding author:

Cosimo Costantino

Department of Biomedical, Biotechnological and

Translational Sciences, University of Parma

Via Gramsci 14

43126 Parma, Italy

E-mail: cosimo.costantino@unipr.it

\section{Summary}

Background: Plantar fasciitis (PF) is reported in different sports mainly in running and soccer athletes. Purpose of this study is to conduct a systematic review of published literature concerning the diagnosis and treatment of PF in both recreational and élite athletes. The review was conducted and reported in accordance with the PRISMA statement.

Methods: The following electronic databases were searched: PubMed, Cochrane Library and Scopus. As far as PF diagnosis, we investigated the electronic databases from January 2006 to June 2016, whereas in considering treatments all data in literature were investigated.

Results: For both diagnosis and treatment, 17 studies matched inclusion criteria. The results have highlighted that the most frequently used diagnostic techniques were Ultrasonography and Magnetic Resonance Imaging. Conventional, complementary, and alternative treatment approaches were assessed.

Conclusions: In reviewing literature, we were unable to find any specific diagnostic algorithm for PF in athletes, due to the fact that no different diagnostic strategies were used for athletes and non-athletes. As for treatment, a few literature da- ta are available and it makes difficult to suggest practice guidelines. Specific studies are necessary to define the best treatment algorithm for both recreational and élite athletes.

Level of evidence: Ib.

KEY WORDS: diagnostic techniques, élite and recreational athletes, plantar fasciitis, plantar fasciopathy, treatment strategies.

\section{Introduction}

The medial longitudinal arch of the foot is sustained by the plantar fascia, a specific subcutaneous structure of dense connective tissue. It can act as a beam when the metatarsals are subjected to important bending forces (propulsion) and a truss when the foot absorbs forces of impact expanded during landing and in the stance phase of gait. The plantar fascia extends from the calcaneus to the distal part of metatarsophalangeal joints of each toe and is divided in central, medial, and lateral sections. The broadest and strongest component of the fascia is the central portion ${ }^{1,2}$. Plantar fasciitis (PF), which is characterized by pain, sharpened with the first walking in the morning or after a long period of rest, develops on the plantar fascia insertion and can be unilateral or bilateral ${ }^{3}$. It is a common cause of foot pain in adults ${ }^{4}$ worsening the patients' quality of life ${ }^{5}$. PF affects both sexes, either in élite or recreational athletes and women are affected slightly more often than men ${ }^{6,7}$. In the United States, more than 1 million patients per year receive healthcare for PF, which is provided by family physician ${ }^{8}$. Even podiatrists, orthopaedic surgeons, physical therapists, and chiropractors are involved in the treatment of PF. In 2007 the cost of treatment of PF in the United States was estimated among \$ 192 to \$ 376 million $^{9}$.

In the past PF was defined as chronic inflammatory condition, nowadays PF is considered a degenerative pathology, more similar to tendinopathy and to a chronic disease which is evident at the site of the attachment of plantar fascia at the medial tubercle of the calcaneus. PF is also referred to plantar heel pain syndrome, heel spur syndrome, plantar fasciopathy or painful heel syndrome $4,10,11$. The acute phase of PF can turn into a chronic phase, which is characterized by a clinical remission and from the progression of the plantar fascia degeneration process ${ }^{3}$.

The risk factors associated with the onset of PF are 
intrinsic and extrinsic. The intrinsic risk factors are associated with body characteristics and include anatomic, functional and degenerative factors. The extrinsic risk factors are associated with physical activities and include overuse, incorrect training and inadequate footwear (Tab. I) ${ }^{4}$.

$\mathrm{PF}$ is experienced in both recreational and élite athletes and is reported in different sports ${ }^{6}$. A recent review concerning ankle and foot injuries in sport, has pointed out that Achilles tendinopathy is the most frequently investigated injury, mostly in running and soccer athletes. Other frequently reported pathologies were stress fracture or PF, mainly reported in basketball players and runners, respectively ${ }^{12}$. These data are in agreement with those detected in élite athletes who competed at the London 2012 Olympic Games ${ }^{13}$. The incidence of PF in runners ranges from 4.5 to $10 \%$, and represents the third most frequently experience running-related musculoskeletal injuries after medial tibial stress syndrome (incidence ranging from 13.6 to $20 \%$ ) and Achilles tendinopathy (incidence ranging from 9.1 to $10.9 \%)^{14}$, in accordance with those previously reported by Taunton et al. ${ }^{7}$. A recent prospective study that analysed the novice running-related injuries, has revealed that PF accounts for about $5 \%$, after medial tibial stress syndrome $(10 \%)$, patellofemoral pain $(10 \%)$, medial meniscal injury ( $9 \%)$, and Achilles tendinopathy
$(7 \%)^{15}$. In ultra-marathon runner athletes PF has an incidence of about $11 \%{ }^{16}$.

The high incidence of PF in runners is not a surprising event if one takes into account the biomechanics of running 17,18 . It is well-known that during running, the vertical ground reaction force acting of foot can double/triple the body weight of athlete and the plantar fascia and longitudinal arch are implicated in the force absorption mechanism. Foot and lower limbs muscles also play a pivotal role in movement patterns of gait and run cycle and, as expected, in the onset and progression of PF. Noteworthy, it was highlighted a difference in rearfoot load in recreational runners with PF, with respect to the stage of disease and with respect to the healthy runners ${ }^{19}$, maybe related to plantar fascia stiffness ${ }^{20}$. This is particularly interesting concerning the development of specific therapeutic and rehabilitation strategies, although more data about plantar loading in athletes are needed.

\section{Diagnosis of PF}

The cardinal symptom of PF is the intense and acute heel pain localized primarily where plantar fascia attaches to the anterior calcaneus. Generally, the pain presents on first walking in the morning or after a rest period, but it can also occur after extensive walking or standing. In athletes, the pain can appear after a

Table I. Principal risk factors associated with Plantar fasciitis.

\begin{tabular}{|c|c|c|}
\hline \multicolumn{2}{|c|}{ Principal risk factors } & \multirow[b]{2}{*}{$\begin{array}{l}\text { Causes } \\
\text { Pes planus } \\
\text { Pes cavus } \\
\text { Overpronation } \\
\text { Leg-length discrepancy } \\
\text { Excessive lateral tibial torsion } \\
\text { Excessive femoral anteversion } \\
\text { Overweight }\end{array}$} \\
\hline \multirow[t]{3}{*}{ Intrinsic } & Anatomic risk & \\
\hline & Functional risk & $\begin{array}{l}\text { Gastrocnemius and soleus muscles tightness } \\
\text { Achilles tendon tightness } \\
\text { Gastrocnemius, soleus and intrinsic foot muscles weakness }\end{array}$ \\
\hline & Degenerative risk & $\begin{array}{l}\text { Aging of the heel fat pad } \\
\text { Atrophy of the heel fat pad } \\
\text { Plantar fascia stiffness }\end{array}$ \\
\hline \multirow{3}{*}{ Extrinsic } & Overuse & Mechanical stresses and microtearing \\
\hline & Incorrect training & $\begin{array}{l}\text { A too-fast increase in the distance, intensity, duration or } \\
\text { frequency of activities that involve repetitive impact loading of } \\
\text { the feet }\end{array}$ \\
\hline & Inadequate footwear & $\begin{array}{l}\text { Poorly cushioned surface } \\
\text { Inappropriate replacement of shoes }\end{array}$ \\
\hline
\end{tabular}


period of intense training, normally declines with the warm up and reappears at the end of training. Foot stiffness and heel swelling is also present ${ }^{4,21}$.

A first approach to diagnose PF is the palpation of both the medial tubercle of the calcaneus and proximal portion of the plantar fascia. For differential diagnosis, ankle passive dorsiflexion, and ankle dorsiflexion/eversion test can be performed to evaluate tarsal tunnel syndrome. Moreover, the Windlass test can be performed to evaluate the plantar fascia loading, albeit this test is characterized by low sensitivity 22 . These manipulations will trigger pain in the subject ${ }^{4,11,21}$. The intrinsic and extrinsic risks associated with the onset and progression of PF are also assessed (Tab. II).

In the case of uncertain diagnosis or when patient presents a persistent heel pain, instrumental analysis can be performed. Diagnostic imaging is recommended when patient suffers of persistent heel pain after 4-6 months of conservative approaches (see below) or in case of atypical symptoms or signs ${ }^{23}$. Plain radiography, magnetic resonance imaging (MRI), diagnostic ultrasonography (US), nerve conduction study and bone scans can be carried out for differential diagnosis. The radiography and bone scans are principally used to rule out bone tumours or fractures ${ }^{4}$. Moreover, plain radiography can detect the presence of subcalcaneal spurs, though their presence is not always associated with the diagnosis of $\mathrm{PF}^{21}$. On the contrary, the other instrumental analyses are used to evaluate the plantar fascia thickness, in order to confirm the diagnosis of PF or plantar fascia rupture and are also used to evaluate inflammatory processes $^{4,21,24}$. In case of bilateral heel pain or in young subjects, specific inflammation markers are also assessed (Tab. II) ${ }^{24}$.

\section{Treatment of PF}

Considering both anamnesis of patient and his physical characteristics, physicians have established a tai- lored treatment protocol. The crucial aims of PF management are the reduction of pain, the improvement of quality of life, including both the return to daily physical activity and physical fitness.

Different approaches are available for the treatment of PF, including drug-, instrumental-, physical-, and surgical-therapy. Furthermore, a growing number of studies are exploring complementary and alternative strategies (Tab. III).

The goal of the non-steroidal anti-inflammatory drugs (NSAIDs) is the reduction of pain. Nowadays is largely accepted that NSAIDs are not used for counteract the physiopathology of PF, considering that PF is a degenerative rather than inflammatory disease. Injections of corticosteroids were also used to treat PF symptoms, preferably ultrasound-guided, because US can be considered an useful tool for monitoring response to treatment ${ }^{25}$. Nevertheless, the side effects of this treatment are not to be underestimated (e.g. fascia rupture and infection) $)^{4,21}$.

Instrumental therapy include laser, extracorporeal shock waves, iontophoresis and ultrasound therapy ${ }^{21}$. Cryoultrasound therapy, a recent strategy that combines ultrasound with cryotherapy, could also be an efficient treatment for pain relief in $\mathrm{PF}^{26}$. Low-dose radiotherapy is another effective therapeutic option in the treatment of enthesiopathies, like PF, with a significant advantage in terms of pain control ${ }^{27}$.

Physical therapy includes massage, manipulative or osteopathic treatments, ice treatments, stretching exercises for foot and lower limbs muscles. Both prefabricated and custom made orthotic devices (e.g. heel cups, insoles and night splints) were used to improve PF symptoms, thanks to the reduction of the pressure on the plantar fascia. Low-dye taping and kinesiotaping are also considered for the treatment of $\mathrm{PF}^{4,6,11}$. Noteworthy, the weight loss is the primary treatment for overweight people (Table III) 4,6 .

An alternative recent therapy is the injection of platelet-rich plasma that contains a large number

Table II. Principal diagnostic elements for Plantar fasciitis.

\begin{tabular}{|c|c|}
\hline Foot palpation & $\begin{array}{l}\text { Medial tubercle of the calcaneus } \\
\text { Proximal portion of the plantar fascia } \\
\text { Ankle passive dorsiflexion/eversion and Windlass test }\end{array}$ \\
\hline Evaluation of intrinsic and extrinsic risks & $\begin{array}{l}\text { Anatomic and functional examination } \\
\text { Physical activity }\end{array}$ \\
\hline Imaging techniques & $\begin{array}{l}\text { Plain radiography } \\
\text { Bone scans } \\
\text { Ultrasonography, sonoelastography } \\
\text { Magnetic Resonance Imaging } \\
\text { Nerve conduction study }\end{array}$ \\
\hline Blood analysis & Inflammation markers \\
\hline
\end{tabular}


Table III. Principal treatment strategies for management of Plantar fasciitis.

\begin{tabular}{l|l}
\hline Drugs & NSAIDs \\
\hline \multirow{3}{*}{ Instrumental } & Laser \\
& Extracorporeal shock waves therapy \\
& Iontophoresis \\
& Ultrasound \\
& Cryoultrasound \\
& Low-dose radiotherapy \\
\hline \multirow{3}{*}{ Physical } & Massage/manual treatments of soft tissues \\
& Osteopathic or manipulative treatments \\
& Stretching \\
& Orthotic devices \\
& Low-dye taping and kinesiotaping \\
\hline \multirow{2}{*}{ Surgery } & Partial or complete fasciotomy \\
& Radiofrequency microtenotomy \\
\hline \multirow{2}{*}{ Complementary and alternative } & Ultrasonic tenotomy \\
\hline & Autologous whole blood and platelet-rich plasma injection \\
& Botulinum toxin injection \\
& Dehydrated amniotic membrane injection \\
\hline
\end{tabular}

growth factors, to promote healing of injured tissues. Autologous whole blood, botulinum toxin, dehydrated amniotic membrane injections were also considered $28-30$.

Surgical intervention is performed when PF symptoms persist after different and repetitive conservative treatments. Generally, partial or complete surgical intervention is recommended after 6-12 months of not effective conservative treatments. Noteworthy side effects for the surgical treatment are reported (e.g. infections, nerve damage and chronic pain) ${ }^{11,21}$. In recalcitrant PF, literature reported promising outcomes with minimally invasive radiofrequency microtenoto$m y^{28}$.

Recent systematic reviews and meta-analysis have evaluated the different treatments available for PF with the aim of determining the most favourable ones. The effectiveness of corticosteroid injections has been shown, albeit the effects are short lasting. With respect to other injection modalities, botulinum toxin injections appear better than corticosteroid injections and corticosteroid injections are better than autologous blood ones $29-31$. Worthy of note is the effect of dehydrated amniotic membrane injection in the shortterm pain relief, with respect to other injection therapies $^{29}$. However, it is necessary to take into consideration that the number of studies regarding these emerging treatments are very limited. Orthotics devices and corticosteroid injections are reported as the best treatment for PF in many studies ${ }^{32}$. Specific stretching exercises for the treatment of PF are the best statistically significant long-term results ${ }^{33}$.

The complete recovery from PF symptoms is a very long process, which usually occurs within two years ${ }^{4}$. Thanks to conservative therapies, about $85-90 \%$ of subjects with PF can be successfully treated ${ }^{11,28}$. Plantar fascia rupture may be a consequence of PF especially in athletes that are subjected to an excessive overload. Nevertheless an adequate post injury protocol can achieve favourable results with complete return to activity ${ }^{34}$.

Recreational and élite athletes who present PF, need to adapt the training parameters such as frequency, intensity and session lasting, because of persistent pain. Obviously, this may be a serious problem because can restrain athletes from sport for a long period, determining the loss of fitness and performances. Indeed, the goal of all athletes is a fast return to preinjury performances.

At present, a lot of literature evaluated the diagnosis and treatment of PF in non-athlete subjects, even if this pathology has a high incidence in athletes ${ }^{35}$. Therefore, the purpose of this study is to conduct a systematic review of published literature concerning the diagnosis and treatment of PF in both élite and recreational athletes.

\section{Methods}

The review was conducted and reported in accordance with the PRISMA statement. The study was 
conducted and meets the ethical standards of the Muscles, Ligaments and Tendon Journal ${ }^{36}$.

\section{Databases and search strategy}

The following electronic databases were searched: PubMed, Cochrane Library and Scopus.

The keywords utilized were "plantar fasciitis", "plantar fasciitis and sport", "plantar fasciitis and élite athletes", "plantar fasciitis and athletes", "diagnosis of plantar fasciitis", "treatment of plantar fasciitis", "plantar fasciopathy", "plantar fasciopathy and sport", "plantar fasciopathy and élite athletes", "plantar fasciopathy and athletes", "diagnosis of plantar fasciopathy" and "treatment of plantar fasciopathy".

As far as PF diagnosis, the electronic databases were investigated from January 2006 until June 2016, whereas for treatments all data were considered until June 2016.

\section{Selection criteria for diagnostic strategies}

In order to find the most current diagnostic strategies for plantar fasciitis we included articles that met the following inclusion criteria:

- athletes and non-athletes aged between 18 years and 75 years;

- in $40 \%$ or more of the sample size was diagnosed with PF;

- comparison of different diagnostic methods and/or comparison between healthy and affected limbs;

- evaluation of at least 10 subjects;

- articles published in English.

Exclusion criteria were as follows:

- military personnel;

- biomechanical studies;

- subjects with systemic diseases in addition to PF. Conference abstracts were evaluated but deemed not suitable because of limited body of data related to the study design and to the intervention program.

\section{Selection criteria for treatment strategies}

Élite athletes are those who dedicate a great time to training in some physical sport disciplines and compete either as individual or as team member at an international, major national or professional level ${ }^{37}$. Analysing current literature we only found 3 studies concerning PF in élite athletes ${ }^{38-40}$, so our research was also extended to recreational ones.

In further analysis, we considered articles that met the following inclusion criteria:

- aged between 18 years and 75 years;

- randomized controlled trials related to both sexes;

- case-reported/case-series studies;

- all types of individual or team sports;

- written in English.

Conference abstracts were evaluated but deemed not suitable because of the limited information available regarding the study design.

\section{Data extraction}

Articles were initially screened by title and abstract. Articles unclear from their title or abstract were re- viewed according the selection criteria through fulltext.

Two Authors (F.P. and I.R.) independently extracted data from the studies that met the inclusion criteria and they were blinded to each other's. In case of disagreement, a third opinion was sought (C.C.). For the 9 studies concerning the diagnosis strategies, the data included were the diagnostic methods and the number of participants. For the 8 studies related to the treatment strategies, the data included were: sport practiced, medical history of subjects, clinical examination, number of participants, treatment plan and outcomes evaluation.

\section{Assessment of risk of bias}

With respect of diagnosis and treatment strategies, the level of evidence were stratified according to the Oxford Centre for Evidence-Based Medicine $(\mathrm{OCEBM})^{41}$.

\section{Results and discussion}

\section{Diagnostic strategies}

Overview of the inclusion process

The reviewing process is presented in Figure $1 \mathrm{a}$. From the initial records retrieved from different databases were excluded duplicate articles, review articles, conference proceeding and book chapters.

From 143 selected articles, 134 did not meet the inclusion criteria as previously reported in methods section. Finally, a total of 9 articles were included in this review ${ }^{42-50}$. The level of evidence of the included articles, according to OCEBM Level of Evidence, is comprised between II and IV.

\section{Details of the included articles}

In the 9 studies included, 2 studies used $\mathrm{MRI}^{42,44}, 6$ used US assessment ${ }^{45-50}$, and 1 study compared US with $M R I^{43}$.

On the basis of literature data, there are not specific studies about diagnosis of PF in élite or non-élite athletes, except for one article that has studied 42 overuse ankle injuries in 18 professional Irish dancers with foot and ankle self-reported questionnaire and MRI. Only 7 athletes showed PF and 3 dancers did not report ankle pain.

Among the other eight articles selected, only one ${ }^{43}$ made a distinction between athletes and not athletes in study population, supposing that participation in competitive sports involving repetitive movements can produces microtears of some fibres of plantar fascia. Sonographic signs like plantar fascia thickness, echogenity, presence or absence of fibre rupture were compared with MRI findings in a total of 23 heels. Five of those were athletes, even if Authors did not specify if professional or recreational. Patients were compared with contralateral heel when symptoms were unilateral and with healthy subjects when symptoms were bilateral ${ }^{43}$.

Karabay et al. have assessed the same US signs in 23 PF patients compared with a control group of 23 


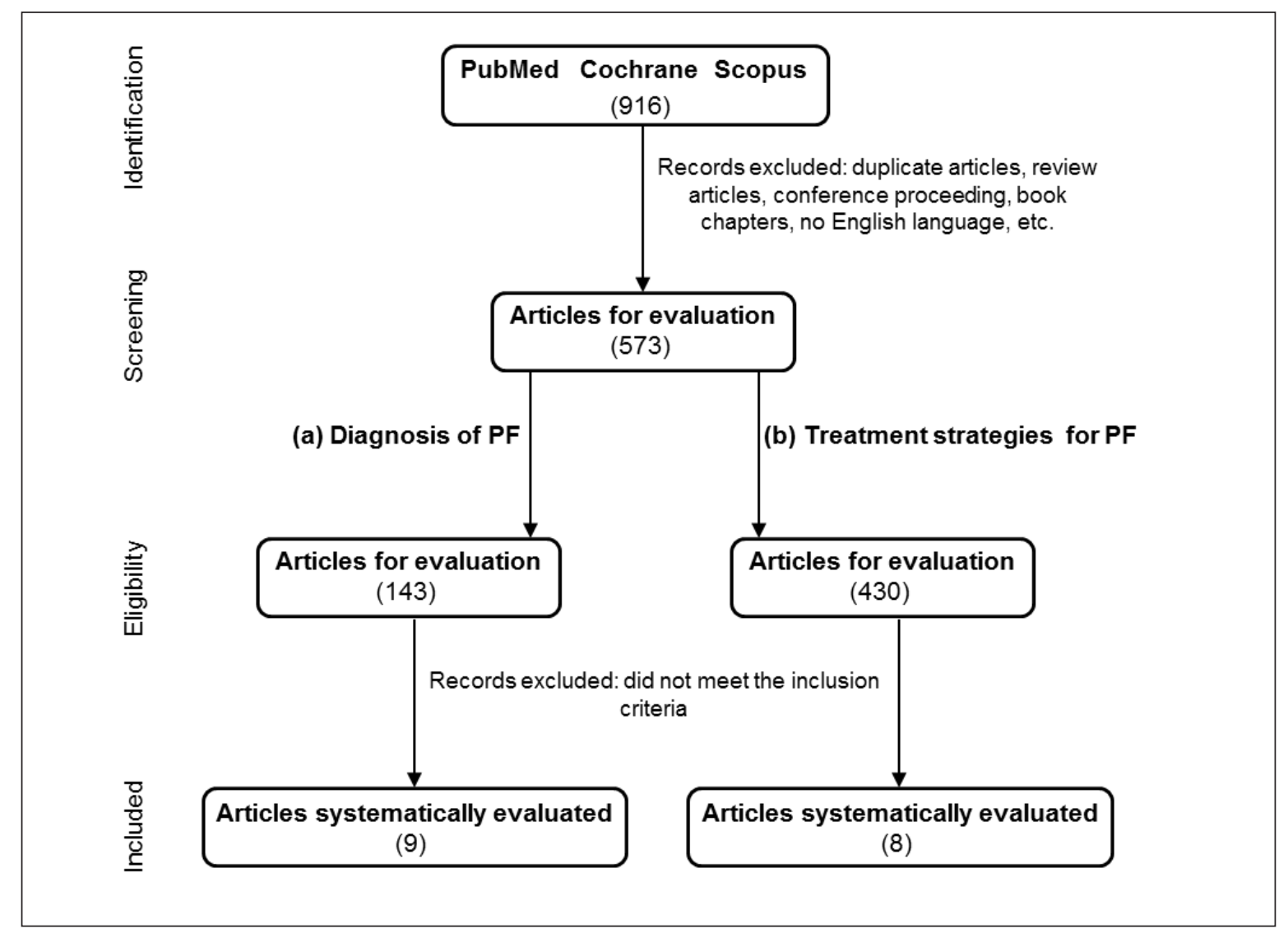

Figure 1. Summary of studies identification and selection for diagnosis (a) and treatment (b) of Plantar fasciitis in athletes.

asymptomatic subjects ${ }^{45}$. In a retrospective blinded study, three radiologists have evaluated thickness and stiffness of plantar fascia with US B-mode and longitudinal elastography between $18 \mathrm{PF}$ feet and 18 healthy subjects ${ }^{46}$.

Sonoelastography was used in another three studies $47,49,50$. In the first study plantar fascia thickness was measured in 80 patients and 50 asymptomatic controls with B-mode US and real-time sonoelastography 47 . In the second study 20 patients and 30 healthy volunteers, all with normal B-mode US findings, were assessed with sonoelastography ${ }^{49}$. In the last study Authors aimed to evaluate reproducibility of sonoelastography with quantitative analysis of echovariation in 23 healthy and 21 symptomatic subjects ${ }^{50}$

A cross-sectional observational study has investigated the presence of soft tissue hyperaemia with power Doppler US in 30 PF participants compared with 30 people age and sex matched ${ }^{48}$.

In a retrospective case series $112 \mathrm{MRI}$ findings were reviewed to confirm PF diagnosis. In the first group of 50 patients with persistent heel pain despite appropriate treatment, 38 confirm the diagnosis of PF. In the second group of 62 patients with atypical symptoms or signs, MRI showed other pathologies in 18 patients ${ }^{44}$.

Imaging studies are not necessary for diagnosis, they are used when pain is resistant to conventional treatment and persist after 4-6 months of conservative treatment and are useful to differentiate other possible causes of heel pain ${ }^{23}$. Imaging studies play a key role in diagnosis and especially in management of PF if physicians are in doubt. Plain radiography is not helpful in direct diagnosis, but is often done to rule out other pathological condition ${ }^{51}$.

Traditional ultrasound evaluation, termed B-mode, is a high resolution real-time examination which offer the unique advantage of dynamic assessment and is very useful in guided injection treatment ${ }^{52}$. Radiologist can use in addition power Doppler assessment in the imaging of active inflammation and elastography that provides a measure of tissue stiffness with gentle manual compression. At US normal plantar fascia is an uniform, fibrillary structure measuring $4 \mathrm{~mm}$ or less, whereas in PF plantar fascia has hypoechoic thickening (> $4 \mathrm{~mm})$, decreased echogenicity and sometimes perifascial effusion ${ }^{45,53}$. Softer stiffness than healthy control can be demonstrated with sonoelastography that is very useful for early diagnosis and in cases of inconclusive B-mode US findings $46,47,49,50$. Hypervascularity involving the fascia and its adjacent soft tissue can be assessed with color Doppler even if clinicians does not consider it as essential for diagno$\mathrm{sis}^{48}$.

The diagnostic accuracy of US is comparable to that 
of MRI in the diagnosis, so clinicians should reserve MRI in selected cases: to confirm diagnosis of PF in patients with persistent or atypical heel pain or to detect other pathologies that may contribute to the aetiology and may be partially responsible for patients complaints (i.e. stress or occult fractures and vascular necrosis) ${ }^{43,44}$.

\section{Treatment strategies}

\section{Overview of the inclusion process}

Concerning to the 430 selected articles about PF treatment, 422 did not meet the inclusion criteria as previously reported in methods section. The remaining 8 articles were included in this review (Fig. 1b) $38-40,54-58$.

\section{Details of the included articles}

The details of the reviewed articles are reported in Table IV. Of the eight studies included, three are related to élite athletes ${ }^{38-40}$ and five are related to recreational athletes ${ }^{54-58}$. Studies concerning élite athletes are two case studies ${ }^{39,40}$ and one case series $^{38}$, even if only one athlete had PF. In these selected articles, the athletes were one soccer player ${ }^{39}$ and one runner ${ }^{40}$, both of 29 years old, and one Australian football player ${ }^{38}$. After the diagnosis of PF, the athletes were subjected to different treatments. In particular, the soccer player was submitted to conservative treatments including taping, orthotic devices, drug and physical therapy, but these approaches did not determine pain relief. Later on, the athlete received two corticosteroid injections, after which he experienced the plantar fascia rupture. The latter was positively treated by platelet-rich plasma therapy ${ }^{39}$. The Australian football player received pregame a ropivacaine injection, and postgame a steroid injection. Both treatments led to an improvement of pain ${ }^{38}$. Firstly, the runner received conventional therapy with limited pain relief. After, he received the ischemic compression therapy associated with calf stretching, which determined an immediate symptoms improvement ${ }^{40}$.

With respect to outcomes therapy, all studies selected have discussed the ability of athletes to maintain their level of training or their ability to perform competitions. This is in accordance with the goal of athletes. Nevertheless, this represents a critical point for the comparative analysis of different treatments because the ability of athletes to continue their physical activity is correlated with their personal perception of pain. On the basis of these three articles it is not possible to determine which is the best treatment for PF in élite athletes. However, is important to underline that side effects have been reported only for corticosteroid injections. Albeit reported the short-term positive effect of this treatment ${ }^{31}$, it is also well documented that corticosteroid injections are correlated to the risk of the plantar fascia rupture ${ }^{31,59}$. However, a recent review and meta-analysis study has not showed this major adverse effect 29 .

Of the eight studies included, four of them considered PF treatments for recreational athletes $55,57,58,60$ and one considered both competitive and recreational athletes ${ }^{56}$. Most of the studies concerns runners, even if one study included basketball players and cyclist $^{57}$ and one study included, but not specified, different sports from running ${ }^{55}$. The number of subjects per study is ranging between $7^{54}$ and $54^{56}$, studies are related to both sex and included subjects of different age. All subjects had previously tried conservative treatments, who have failed to determine a pain relief (Tab. IV).

The extracorporeal shock wave therapy (ESWT) is the most frequently reported treatment. In particular, one study 56 has considered the effect of low-dose ESWT treatment on both competitive and recreational joggers. The results have highlighted a good or excellent pain improvement assessed by Visual Analog Scale (VAS). Data have been confirmed at 24-month follow-up. Moreover, the treatment has determined a reduction of inflammatory signs at follow-up. Only four athletes on 54 (8\%) were unsatisfactory. Adverse effects were not reported in this study.

One study ${ }^{58}$ has assessed the effects of ESWT with respect to a sham treatment. In agreement with previous reported study, the results have underlined the lasting pain improvement evaluated by VAS, at 6 and 12 months follow-up. Data have been confirmed also by secondary outcomes. At 12-month follow-up 3 on 22 subjects in treatment group and 3 on 23 subjects in sham group have considered the treatment ineffective. However, concurrent treatments have been reported for both treatment and sham groups, even if it remains at a comparable level between groups. These studies have also revealed that patients have considered the therapy unpleasant but without major adverse effects.

One study ${ }^{55}$ has compared ESWT treatment with both placebo group ( $p E S W T$ ) and surgical therapy (EPF). The therapy outcomes, assessed by VAS and Roles and Maudlsey (RM), have determined a statistical improvement for both ESWT and EPF group, but EPF group was significantly better than the other groups. In contrast, athletes of ESWT group were able to return-to-activity in a time ranging between immediate and two months after treatment, while EPF group was able to return-to-activity after an average of 2.8 months. Athletes belonging to pESWT group were able to return-to-activity in a time ranging between immediate and six months. No adverse effects of treatments were reported.

The other two selected studies have evaluated surgical treatment and rehabilitative physical therapy, respectively (Tab. IV). The results concerning the plantar fasciotomy ${ }^{57}$ have highlighted an excellent/good pain relief evaluated by Modified Plantar Fascia Score (MPFS). Athletes were able to return-to-activity after an average of $2.7 \pm 0.7$ months after surgery. Adverse effects of treatment were reported. With respect to the Primal Reflex Release Technique $(\mathrm{PRRT})^{54}$ is a manual-therapy approach that involves down regulation of an overstimulated autonomic nervous system with the aim to reduce patterns of pain. 


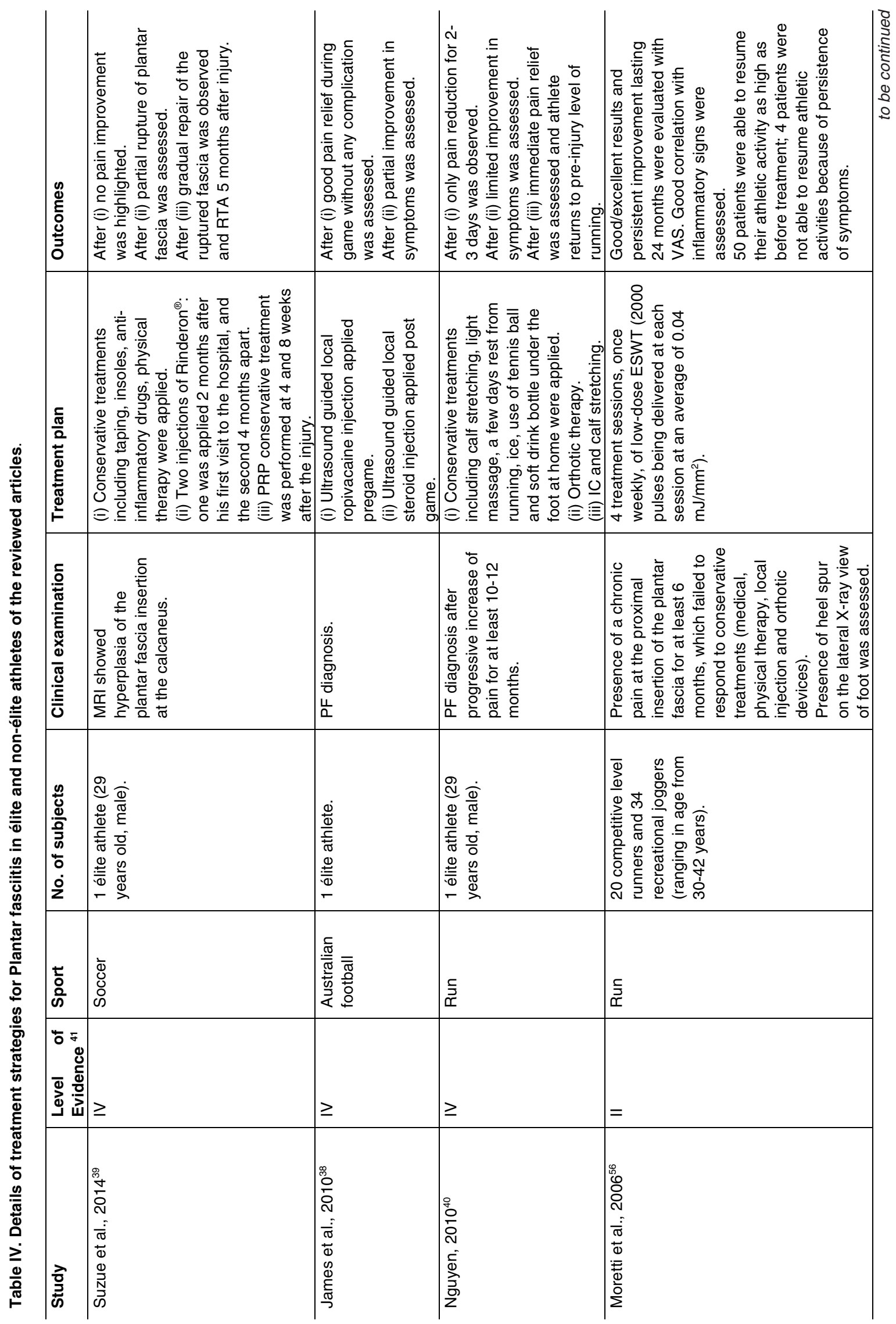




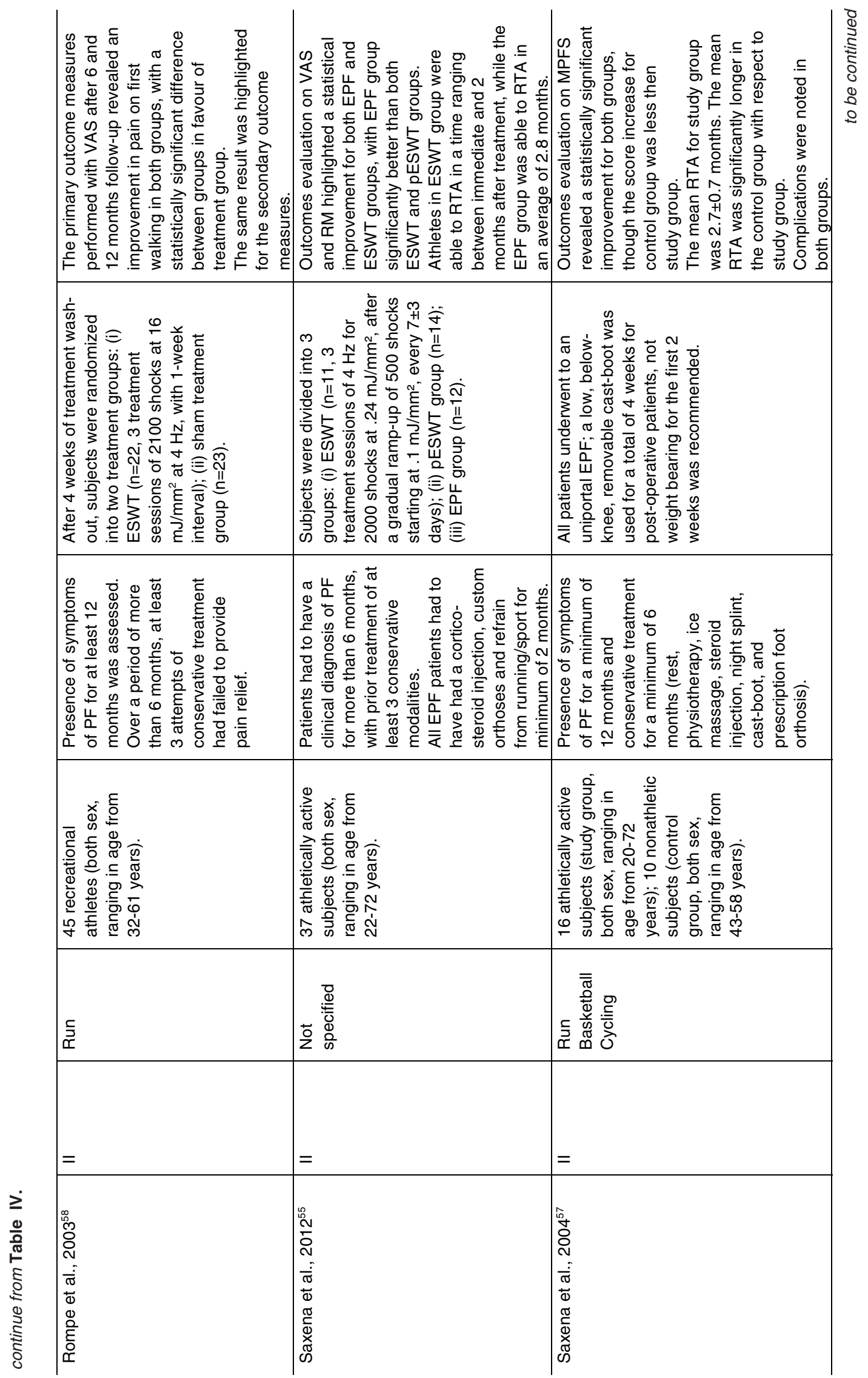




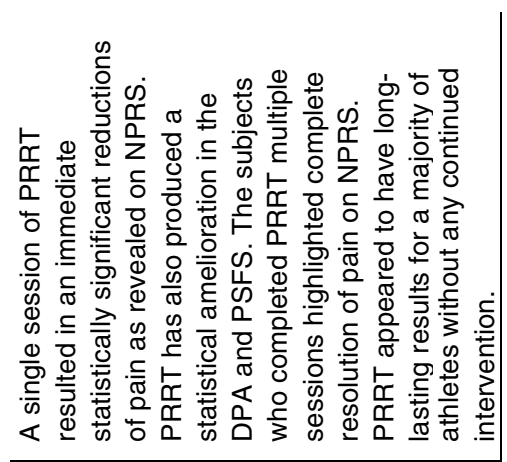

\section{范

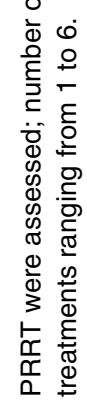

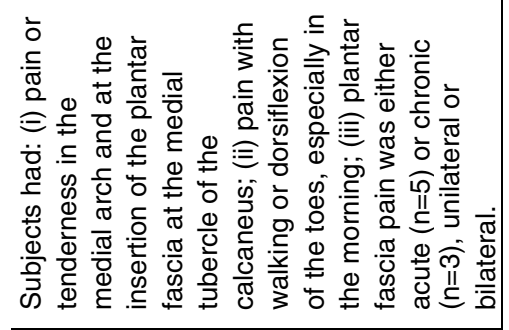
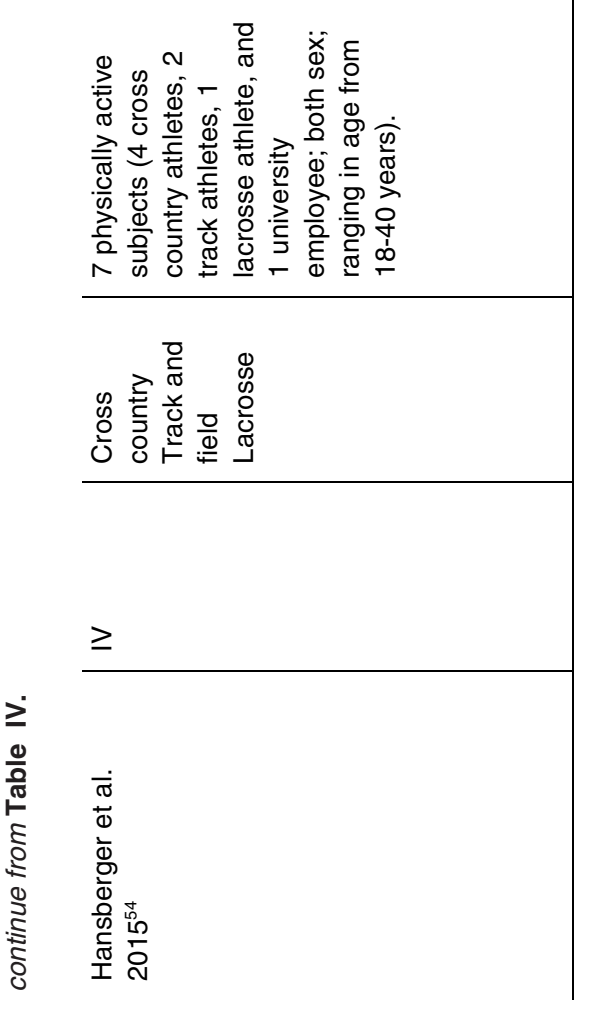

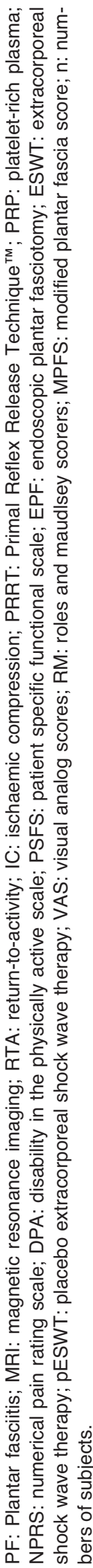

The results have highlighted that only a single session is able to determine an immediate amelioration in pain as assessed by the Numeric Pain Rating Scale (NPRS), the Disability in the Physically Active (DPA) Scale, and the Patient Specific Functional Scale (PSFS). The beneficial effects have also appeared to be long-lasting. Unfortunately, this study has not discussed the return-to-activity of athletes.

On the basis of the reviewed articles the ESWT seems to be a good strategy for the management of PF in recreational athletes. ESWT offers the advantage of a fast return-to-activity after treatment or the possibility to combine therapy and physical activity. Authors report also good results with both PRRT and uniportal endoscopic plantar fasciothomy strategies, even if the latter imply a return-to-activity longer than ESWT.

The limitation of this review is related to the fewer available studies concerning both diagnosis and treatment of PF in élite and recreational athletes. For this reason we have not imposed an assessment of methodological quality of selected articles but we included all studies founded during literature reviewed process. On the basis of these evidence, we can not perform a meta-analysis. As regards the treatment of PF we would like to underline that studies included are heterogeneous in term of treatment strategies, number of subjects, primary and secondary outcomes, and follow-up.

\section{Conclusion}

In this review of the literature it has not been possible to highlight any specific diagnostic algorithm for PF in both recreational and élite athletes. There are not evidence of different diagnostic strategies for athletes and non-athletes.

Different associations gave their clinical recommendations $^{61,62}$ for PF but there are not specific Practice Guidelines neither for élite athletes nor for recreational athletes. Despite of the literature, causes of PF are multifactorial and remain poorly understood for many patients in clinical practice. Clinical Practice Guidelines from the Orthopaedic Section of the American Physical Therapy Association ${ }^{61}$ recommend that clinicians should assess the presence of limited ankle dorsiflexion range of motion, high body mass index in nonathletic individuals, running, and work-related weight-bearing activities, particularly under conditions with poor shock absorption, as risk factors for the development of heel pain/plantar fasciitis (moderate grade of evidence). Diagnosis of PF is made on the basis of a clinical assessment or after an accurate physical examination using the following physical examination findings:

- plantar medial heel pain (most noticeable with initial steps after a period of inactivity but also worse following prolonged weight bearing);

- heel pain precipitated by a recent increase in weightbearing activity;

- pain with palpation of the proximal insertion of the 
plantar fascia;

- positive Windlass test (evaluation of plantar fascia loading);

- negative tarsal tunnel tests (dorsiflexion/eversion test);

- limited active and passive talocrural joint dorsiflexion range of motion;

- abnormal Foot Posture Index Score (quantification of standing foot posture);

- high body mass index in nonathletic individuals. Physicians can classify a patient with the International Classification of Functioning, Disability and Health (ICF) impairment-based category of heel pain (with code b28015: Pain in lower limb, and code b2804: Radiating pain in a segment or region).

Clinicians should use validated self-reported questionnaire (strong level of evidence: IA) like the Foot and Ankle Ability Measure (FAAM), the Foot Function Index (FFI) or the Foot Health Status Questionnaire (FHSQ) that are cross-cultural adapted and validated in different languages, in order to define activity limitation, physical impairments and participation restrictions associated ${ }^{61}$.

Concerning treatment in athletes is quite difficult to suggest practice guidelines on the basis of few literature data. Specific studies are necessary to define the best treatment algorithm for both recreational and élite athletes.

\section{References}

1. Benjamin M. The fascia of the limbs and back-a review. J Anat. 2009;214(1):1-18.

2. McNally EG, Shetty S. Plantar fascia: imaging diagnosis and guided treatment. Semin Musculoskelet Radiol. Sep 2010; 14(3):334-343

3. League AC. Current concepts review: plantar fasciitis. Foot Ankle Int. 2008;29(3):358-366.

4. Young $\mathrm{C}$. In the clinic. Plantar fasciitis. Ann Intern Med 2012;156(1 Pt 1):ITC1-1, ITC1-2, ITC1-3, ITC1-4, ITC1-5, ITC1-6, ITC1-7, ITC1-8, ITC1-9, ITC1-10, ITC11-11, ITC1112, ITC11-13, ITC11-14, ITC11-15; quiz ITC11-16.

5. Irving DB, Cook JL, Young MA, Menz HB. Impact of chronic plantar heel pain on health-related quality of life. J Am Podiatr Med Assoc. 2008;98(4):283-289.

6. Orchard J. Plantar fasciitis. BMJ. 2012;345:e6603.

7. Taunton JE, Ryan MB, Clement DB, McKenzie DC, LloydSmith DR, Zumbo BD. A retrospective case-control analysis of 2002 running injuries. Br J Sports Med. 2002;36(2):95-101.

8. Riddle DL, Schappert SM. Volume of ambulatory care visits and patterns of care for patients diagnosed with plantar fasciitis: a national study of medical doctors. Foot Ankle Int 2004;25(5):303-310.

9. Tong KB, Furia J. Economic burden of plantar fasciitis treatment in the United States. Am J Orthop (Belle Mead NJ). 2010;39(5):227-231.

10. Stuber K, Kristmanson K. Conservative therapy for plantar fasciitis: a narrative review of randomized controlled trials. $J$ Can Chiropr Assoc. 2006;50(2):118-133.

11. Thompson JV, Saini SS, Reb CW, Daniel JN. Diagnosis and management of plantar fasciitis. J Am Osteopath Assoc. 2014:114(12):900-906.

12. Sobhani S, Dekker R, Postema K, Dijkstra PU. Epidemiology of ankle and foot overuse injuries in sports: A systematic re- view. Scand J Med Sci Sports. 2013;23(6):669-686.

13. Elias DA, Carne A, Bethapudi S, Engebretsen L, Budgett R, O'Connor P. Imaging of plantar fascia and Achilles injuries undertaken at the London 2012 Olympics. Skeletal Radiol. 2013:42(12):1645-1655.

14. Lopes AD, Hespanhol Junior LC, Yeung SS, Costa LO. What are the main running-related musculoskeletal injuries? A Systematic Review. Sports Med. 2012;42(10):891-905.

15. Nielsen RO, Ronnow L, Rasmussen S, Lind M. A prospective study on time to recovery in 254 injured novice runners. PLoS One. 2014;9(6):e99877.

16. Hoffman MD, Krishnan E. Health and exercise-related medical issues among 1,212 ultramarathon runners: baseline findings from the Ultrarunners Longitudinal TRAcking (ULTRA) Study. PLoS One. 2014;9(1):e83867.

17. Murphy K, Curry EJ, Matzkin EG. Barefoot running: does it prevent injuries? Sports Med. 2013;43(11):1131-1138.

18. Bolgla LA, Malone TR. Plantar fasciitis and the windlass mechanism: a biomechanical link to clinical practice. J Athl Train. 2004;39(1):77-82.

19. Ribeiro AP, Joao SM, Dinato RC, Tessutti VD, Sacco IC. Dynamic Patterns of Forces and Loading Rate in Runners with Unilateral Plantar Fasciitis: A Cross-Sectional Study. PLoS One. 2015;10(9):e0136971.

20. Wu CH, Chang KV, Mio S, Chen WS, Wang TG. Sonoelastography of the plantar fascia. Radiology. 2011;259(2):502507.

21. Goff JD, Crawford R. Diagnosis and treatment of plantar fasciitis. Am Fam Physician. 2011;84(6):676-682.

22. De Garceau D, Dean D, Requejo SM, Thordarson DB. The association between diagnosis of plantar fasciitis and Windlass Test results. Foot \& Ankle International. 2003;24(3):251-255.

23. Neufeld SK, Cerrato R. Plantar fasciitis: evaluation and treatment. J Am Acad Orthop Surg. 2008;16(6):338-346.

24. Cutts S, Obi N, Pasapula C, Chan W. Plantar fasciitis. Ann R Coll Surg Engl. 2012;94(8):539-542.

25. Mahmoud Ali Moustafa A. Objective assessment of corticosteroid effect in plantar fasciitis: additional utility of ultrasound. Muscles, Ligaments and Tendons Journal. 2015.

26. Costantino C, Vulpiani MC, Romiti D, Vetrano M, Saracen VM. Cryoultrasound therapy in the treatment of chronic plantar fasciitis with heel spurs. A randomized controlled clinical study. Eur J Phys Rehabil Med. 2014;50(1):39-47.

27. Ott OJ, Niewald M, Weitmann HD, et al. DEGRO guidelines for the radiotherapy of non-malignant disorders. Part II: Painful degenerative skeletal disorders. Strahlenther Onkol. 2015 191(1):1-6.

28. Miller LE, Latt DL. Chronic Plantar Fasciitis is Mediated by Local Hemodynamics: Implications for Emerging Therapies. N Am J Med Sci. 2015;7(1):1-5.

29. Tsikopoulos K, Vasiliadis HS, Mavridis D. Injection therapies for plantar fasciopathy ('plantar fasciitis'): a systematic review and network meta-analysis of 22 randomised controlled trials. Br J Sports Med. 2016.

30. Tsikopoulos K, Tsikopoulos A, Natsis K. Autologous whole blood or corticosteroid injections for the treatment of epicondylopathy and plantar fasciopathy? A systematic review and meta-analysis of randomized controlled trials. Phys Ther Sport. 2016

31. Ang TW. The effectiveness of corticosteroid injection in the treatment of plantar fasciitis. Singapore Med J. 2015;56 (8):423-432.

32. Lewis RD, Wright $\mathrm{P}, \mathrm{McC}$ arthy LH. Orthotics Compared to Conventional Therapy and Other Non-Suraical Treatments for Plantar Fasciitis. J Okla State Med Assoc. 2015;108(12):596598.

33. Schwartz EN, Su J. Plantar fasciitis: a concise review. Perm J. 2014;18(1):e105-107. 
34. Saxena A. Plantar Fascia Ruptures in Athletes. American Journal of Sports Medicine. 2004;32(3):662-665.

35. Tahririan MA, Motififard M, Tahmasebi MN, Siavashi B. Plantar fasciitis. J Res Med Sci. 2012;17(8):799-804.

36. Padulo J, Oliva F, Frizziero A, Maffulli N. Muscles, Ligaments and Tendons Journal - Basic principles and recommendations in clinical and field Science Research: 2016 Update. MLTJ. 2016;6(1):1-5.

37. Segen JC. Concise dictionary of modern medicine. New York; London: McGraw-Hill. 2006.

38. James $\mathrm{P}, \mathrm{Barbour} \mathrm{T}$, Stone $\mathrm{I}$. The match day use of ultrasound during professional football finals matches. Br J Sports Med. 2010;44(16):1149-1152.

39. Suzue N, Iwame T, Kato K, et al. Plantar fascia rupture in a professional soccer player. J Med Invest. 2014;61(3-4):413-416.

40. Nguyen BM. Trigger point therapy and plantar heel pain: A case report. Foot (Edinb). 2010;20(4):158-162.

41. OCEBM Levels of Evidence Working Group. The Oxford 2011 Levels of Evidence. Oxford Centre for Evidence Based Medicine. Available at: http://www.cebm.net/index.aspx? $0=5653$.

42. Walls RJ, Brennan SA, Hodnett P, O'Byrne JM, Eustace SJ, Stephens MM. Overuse ankle injuries in professional Irish dancers. Foot Ankle Surg. 2010;16(1):45-49.

43. Abdel-Wahab N, Fathi S, Al-Emadi S, Mahdi S. High-resolution ultrasonographic diagnosis of plantar fasciitis: a correlation of ultrasound and magnetic resonance imaging. International Journal of Rheumatic Diseases. 2008;11(3):279-286.

44. Chimutengwende-Gordon M, O'Donnell P, Singh D. Magnetic resonance imaging in plantar heel pain. Foot Ankle Int. 2010; 31(10):865-870.

45. Karabay $\mathrm{N}$, Toros $\mathrm{T}$, Hurel $\mathrm{C}$. Ultrasonographic evaluation in plantar fasciitis. J Foot Ankle Surg. 2007;46(6):442-446.

46. Lee SY, Park HJ, Kwag HJ, et al. Ultrasound elastography in the early diagnosis of plantar fasciitis. Clin Imaging. 2014;38 (5):715-718.

47. Sconfienza LM, Silvestri E, Orlandi D, et al. Real-time sonoelastography of the plantar fascia: comparison between patients with plantar fasciitis and healthy control subjects. Radiology. 2013;267(1):195-200.

48. McMillan AM, Landorf KB, Gregg JM, De Luca J, Cotchett MP, Menz HB. Hyperemia in plantar fasciitis determined by power Doppler ultrasound. J Orthop Sports Phys Ther. 2013;43 (12):875-880.

49. Wu CH, Chen WS, Wang TG. Plantar fascia softening in plantar fasciitis with normal B-mode sonography. Skeletal Radiol.
2015;44(11):1603-1607.

50. Rios-Diaz J, Martinez-Paya JJ, del Bano-Aledo ME, de GrootFerrando A, Botia-Castillo P, Fernandez-Rodriguez D. Sonoelastography of Plantar Fascia: Reproducibility and Pattern Description in Healthy Subjects and Symptomatic Subjects. UItrasound Med Biol. 2015;41(10):2605-2613.

51. Joong MA, El-Khoury GY. Radiologic evaluation of chronic foot pain. American Family Physician. 2007;76(7):975-983.

52. Doody O, Hopper MA. Imaging of the foot and ankle. Orthopaedics and Trauma. 2014;28(5):339-349.

53. Chen CK, Lew HL, Chu NC. Ultrasound-guided diagnosis and treatment of plantar fasciitis. Am J Phys Med Rehabil. 2012; 91(2):182-184.

54. Hansberger BL, Baker RT, May J, Nasypany A. A Novel Approach to Treating Plantar Fasciitis - Effects of Primal Reflex Release Technique: A Case Series. Int J Sports Phys Ther. 2015;10(5):690-699.

55. Saxena A, Fournier M, Gerdesmeyer L, Gollwitzer H. Comparison between extracorporeal shockwave therapy, placebo ESWT and endoscopic plantar fasciotomy for the treatment of chronic plantar heel pain in the athlete. Muscles Ligaments Tendons J. 2012;2(4):312-316.

56. Moretti B, Garofalo R, Patella V, Sisti GL, Corrado M, Mouhsine E. Extracorporeal shock wave therapy in runners with a symptomatic heel spur. Knee Surg Sports Traumatol Arthrosc. 2006;14(10):1029-1032.

57. Saxena A. Uniportal endoscopic plantar fasciotomy: a prospective study on athletic patients. Foot Ankle Int. 2004; 25(12):882-889.

58. Rompe JD, Decking J, Schoellner C, Nafe B. Shock wave application for chronic plantar fasciitis in running athletes. A prospective, randomized, placebo-controlled trial. Am J Sports Med. 2003;31(2):268-275.

59. Lee HS, Choi YR, Kim SW, Lee JY, Seo JH, Jeong JJ. Risk factors affecting chronic rupture of the plantar fascia. Foot Ankle Int. 2014;35(3):258-263.

60. Felix JF, Bradfield JP, Monnereau C, et al. Genome-wide association analysis identifies three new susceptibility loci for childhood body mass index. Hum Mol Genet. 2016;25(2):389403.

61. Martin RL, Davenport TE, Reischl SF, et al. Heel pain-plantar fasciitis: revision 2014. J Orthop Sports Phys Ther. 2014;44 (11):A1-33.

62. Thomas JL, Christensen JC, Kravitz SR, et al. The diagnosis and treatment of heel pain: a clinical practice guideline-revision 2010. J Foot Ankle Surg. 2010;49(3 Suppl):S1-19. 